\title{
Effects of hepatitis C virus NS3 protein on expression of heat shock protein 70 and Glypican3 as the markers of hepatocellular carcinoma
}

\author{
Sepideh Saeb ${ }^{(1}{ }^{1}$, Farzaneh Sabahi ${ }^{1 *}{ }^{*}$, Zohreh Mazaheri $^{\left({ }^{2}\right.}{ }^{2}, \operatorname{Mehrdad~Ravanshad}^{\left({ }^{1 *}\right.}$
}

\begin{abstract}
Background and Aims: Hepatitis $\mathrm{C}$ virus $(\mathrm{HCV})$ infection is an important risk factor for the development of liver cancer. The HCV NS3 protein plays a key role in the virus life cycle and can affect normal cellular activities, such as cell proliferation, cell death, and cell signaling pathways. Moreover, it may influence malignancy development. Two cellular genes, heat shock protein 70 (HSP70) and Glypican3 (GPC3), that are assessed in this study, play important roles in the regulation of the cell signaling pathways, including cell proliferation. This study aimed to evaluate the effects of HCV NS3 protein on the expressions of these two genes in the Balb/C mouse model.

Materials and Methods: This study was performed on three groups of male mice of $B a l b / C(n=8)$. The first group received NS3 plasmid, the second group received hepatitis B virus HBx plasmid, and the negative control group received distilled water. Two injections were administered via the tail vein, and after the last injection, RNA was extracted from the liver tissue. Next, the cDNA synthesis and real-time polymerase chain reaction for relevant genes were performed.

Results: Findings revealed that the relative expression of the selected genes in the NS3 group was significant in comparison with the negative control group ( $\mathrm{P}=0.0229$ for GPC3 and 0.0020 for HSP70). However, there was no significant difference between the NS3 group and the HBx group ( $\mathrm{P}=0.4516$ for GPC 3 and 0.6740 for HSP70).

Conclusion: Results showed that NS3 protein may affect the increasing expression of the mentioned genes. Nevertheless, for more precise understanding, much more studies should be performed, such as evaluation of the effect of NS3 on other involved proteins in cell signaling pathways, studying other domains of NS3, performance of pathological and histological tests, usage of various experimental methods, assessment of the role of NS4A as a cofactor for NS3, and usage of vectors with more stability.
\end{abstract}

Keywords: Glypican3, Hepatitis C virus, Hepatocellular carcinoma, HSP70, NS3

Citation: Saeb S, Sabahi F, Mazaheri Z, Ravanshad M. [Effects of hepatitis C virus NS3 protein on expression of heat shock protein 70 and Glypican3 as the markers of hepatocellular carcinoma]. J Birjand Univ Med Sci. 2021; 28(4): 356-364. [Persian]

DOI http://doi.org/10.32592/JBirjandUnivMedSci.2021.28.4.104

Received: May 10, 2021

Accepted: October 10, 2021

\footnotetext{
${ }^{1}$ Department of Virology, Faculty of Medical Sciences, Tarbiat Modares University, Tehran, Iran

${ }^{2}$ Basic Medical Sciences Research Center, Histogenotech Co, Tehran, Iran

* Corresponding author:

1. Department of Virology, Faculty of Medical Sciences, Tarbiat Modares University, Tehran, Iran.

E-mail: Ravanshad@modares.ac.ir Tel: +9821-82883836

2. Department of Virology, Faculty of Medical Sciences, Tarbiat Modares University, Tehran, Iran.

E-mail: sabahi_f@modares.ac.ir

Tel: +9821-82883836
} 


\title{
اثر بروتئين NS3 ويروس هياتيت سى بر القاى بيان نشانكر هاى HSP70 و Glypican3 كارسينوماى هياتوسلولار
}

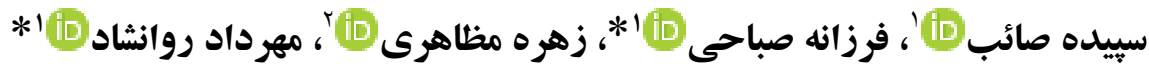

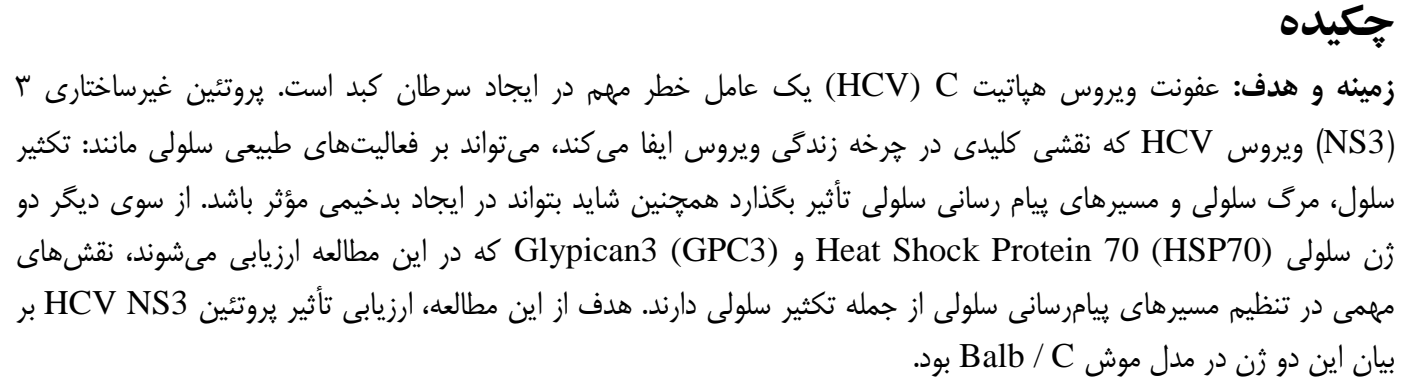

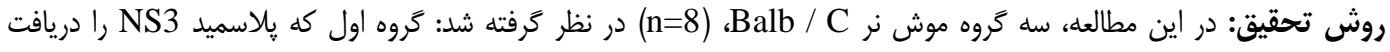

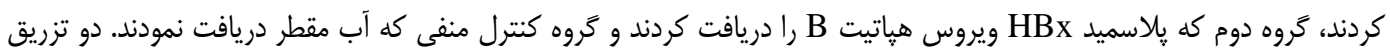

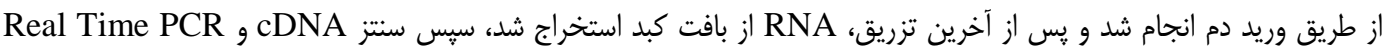

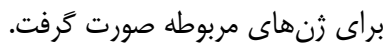

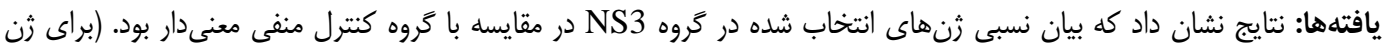

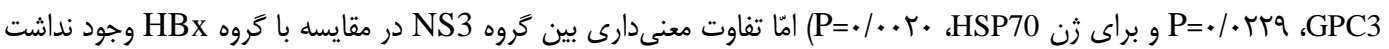

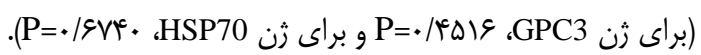

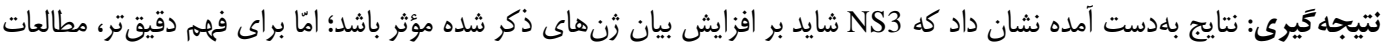

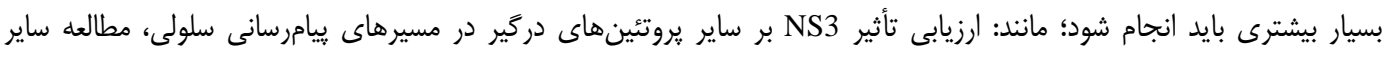

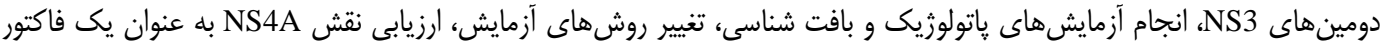

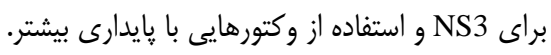

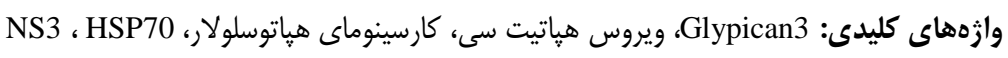

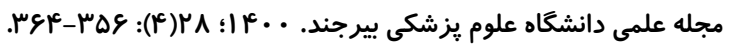

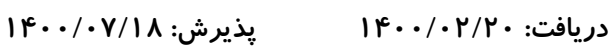

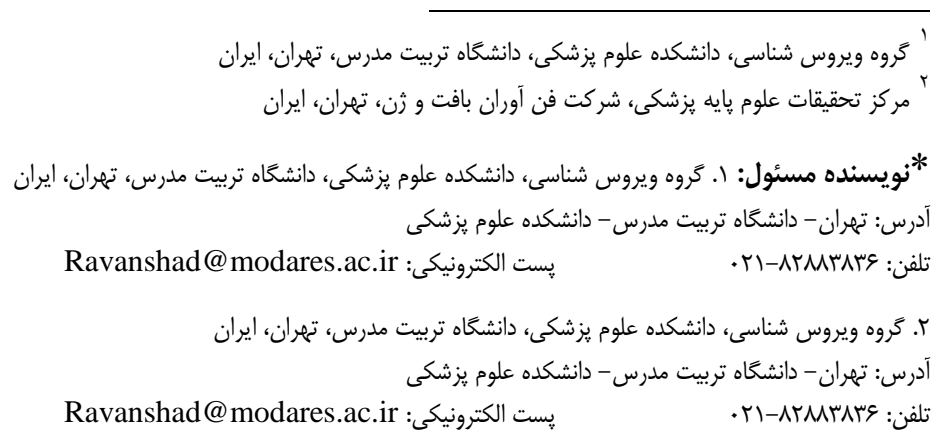


جمله تغييرات انكوزنز القا مىشود (1). HSP70 ممكن است در

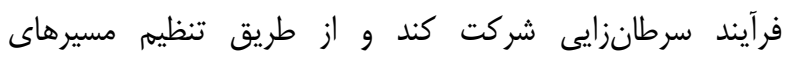
آيويتوتيك، تكثير و بقاى سلولهاى تومورى را تغيير دهد. بيان

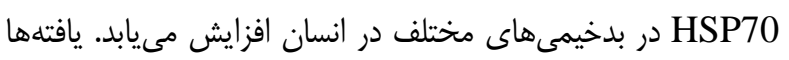

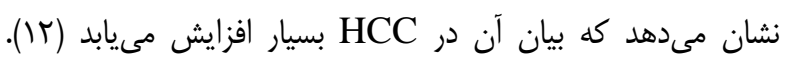

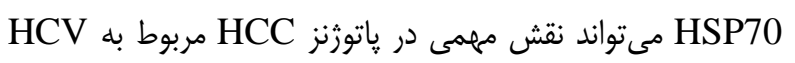

$$
\text { داشته باشد (T) (1) (1). }
$$

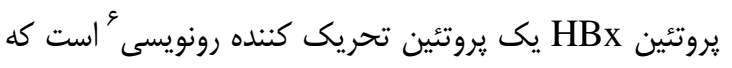
توسط ويروس هياتيت HBV) Bد مد مىشود و مىتواند در سرطان كبد نقش داشته باشد. HBx با اهداف مختلف ميزبانى و با بسيارى

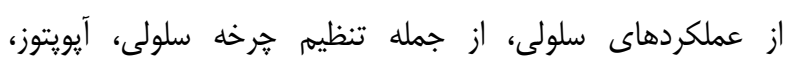

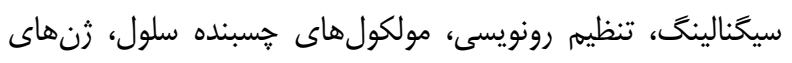

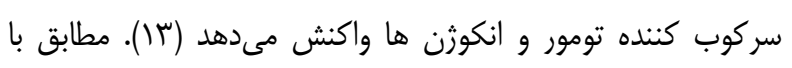

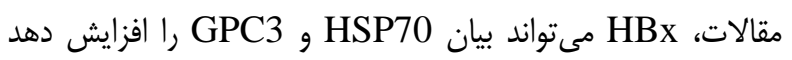

(I)-IV) هدف از اين مطالعه، ارزيابى اثر حضور يروتئين NS3 بر تغيير

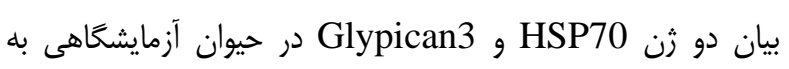

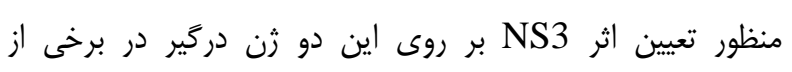

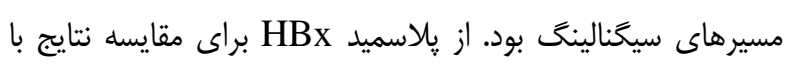

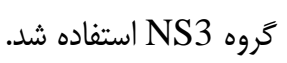

\section{روش تحقيق

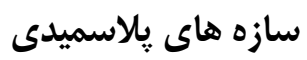 يلاسميد NS3 هازي تلاسمي}

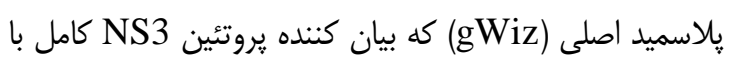

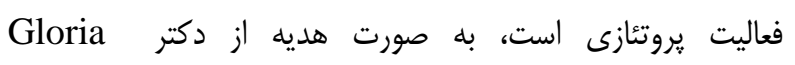
Gonzalez-Aseguinolaza (مركز تحقيقات CIMA، ناوارا، اسِانيا) دريافت شد (تصوير (). بيان يروتئين NS3 تحت كنترل يروموتر Cytomegalovirus(CMV) است و تأييد توالى و بيان

$$
\text { آن قبلاً انجام شده است (1) (1). }
$$

\footnotetext{
${ }^{6}$ Transactivator of transcription protein $\mathrm{HBx}$
}

\section{مقاله}

ويروس هياتيت يك ويروس يوششدار داراى (HCV) C زنوم RNA تك رشتهاى با پلاريته مثبت مىباشد كه به خانواده Flaviviridae

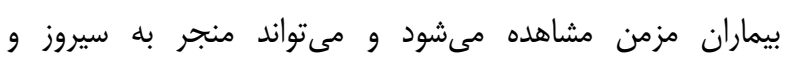

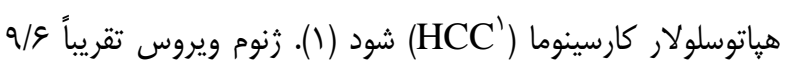

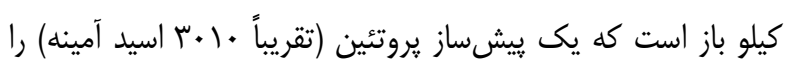

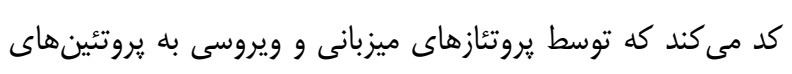

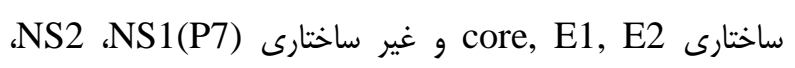

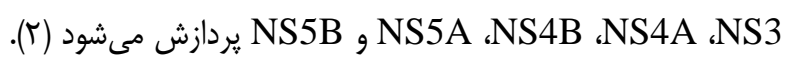
NS3 ${ }^{r}$

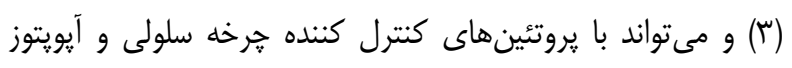

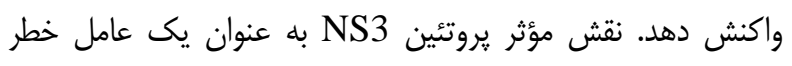

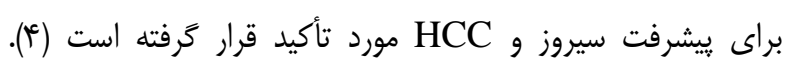

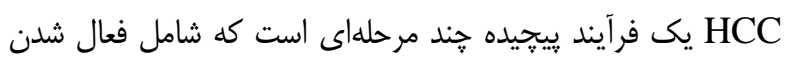

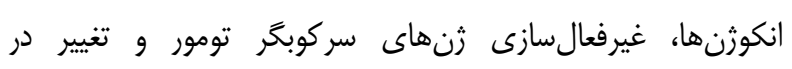

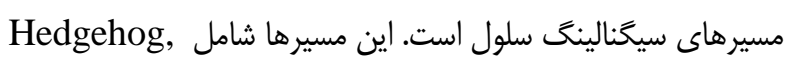
Notch, WNT/ $\beta$-Catenin, p53, pRb, TGF- $\beta$ است (D-V). تعداد زيادى نشانگر بافتى و سرمى با تهاجم، متاستاز،

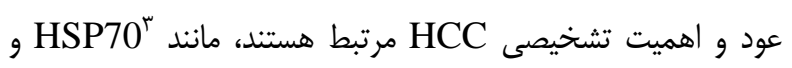

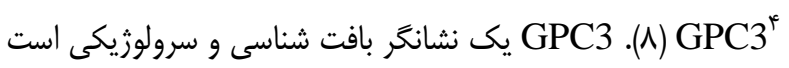
و بيان آن در HCC تا حدى اختصاصى است (9). انكوزنيسيته با

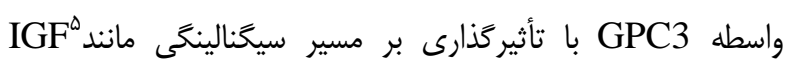

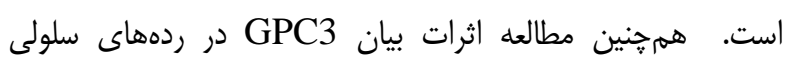

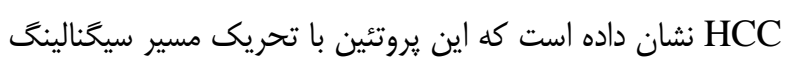
Canonical / Wnt

يكى از اعضاى خانواده بروتئينهاى شوى كرمايى HSP70

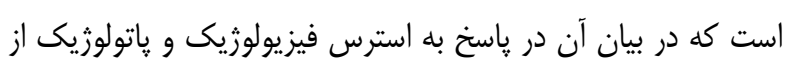

\footnotetext{
${ }^{1}$ Hepatocellular carcinoma

${ }^{2}$ Non structural protein 3

${ }^{3}$ Heat shock protein 70

${ }^{4}$ Glypican3

${ }^{5}$ Insulin like growth factor
} 


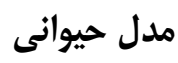

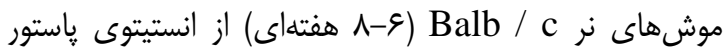
ايران (كرج، ايران) خريدارى شده و به سه كروه ^ نايى تقسيم شدند.

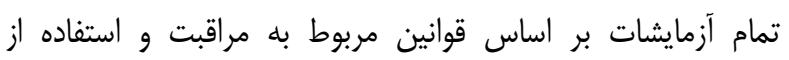

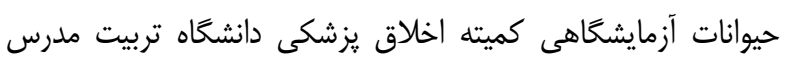

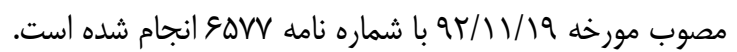

\section{استخراج و تزريق یلاسميدها}

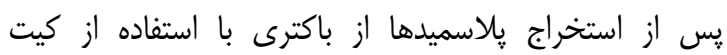

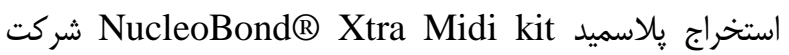
آلمان، مرحله تزريق پِاسميدها انجام شد. يّ از ضد ضد عفونى كردن دم با الكل، با استفاده از سرنح انسولين، حداكثر مقدار ...

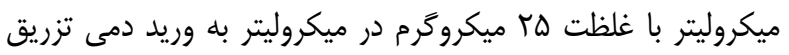

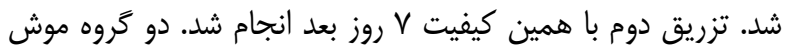

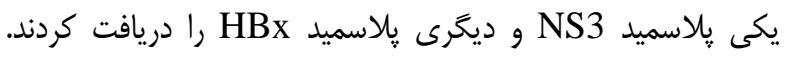
كروه سوم نيز به عنوان كنترل منفى، آب مقطر دريافت نمودند.

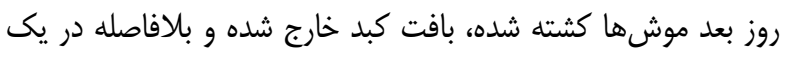
ميلىليتر محلول ترايزول در فريزر منفى •V درجه سانتى رَاد قرار داده شد.

استخراج RNA، ساخت CDNA و انجام Real Time PCR

Trizole تام بافت كبدى با استفاده از محلول RNA (Qiagen)

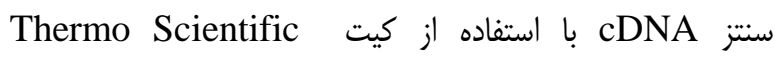

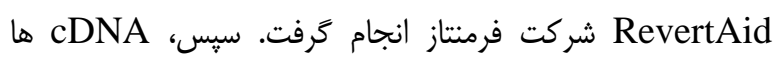
براى انجام Real-Time PCR استفاده شدند. جهت انجام اين كار براى هر بار تست، مواد زير به نسبتهاى كفته شده در داخل ظروف ^^ خانه ريخته و با يكديخر تركيب شدند. اين مواد شامل: به ميزان (ABI, USA) CYBER Green Master Mix

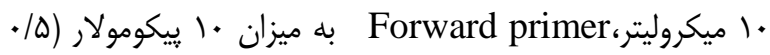
ميكروليتر)، Reverse primer به ميزان •. بيكومولار (ه/.
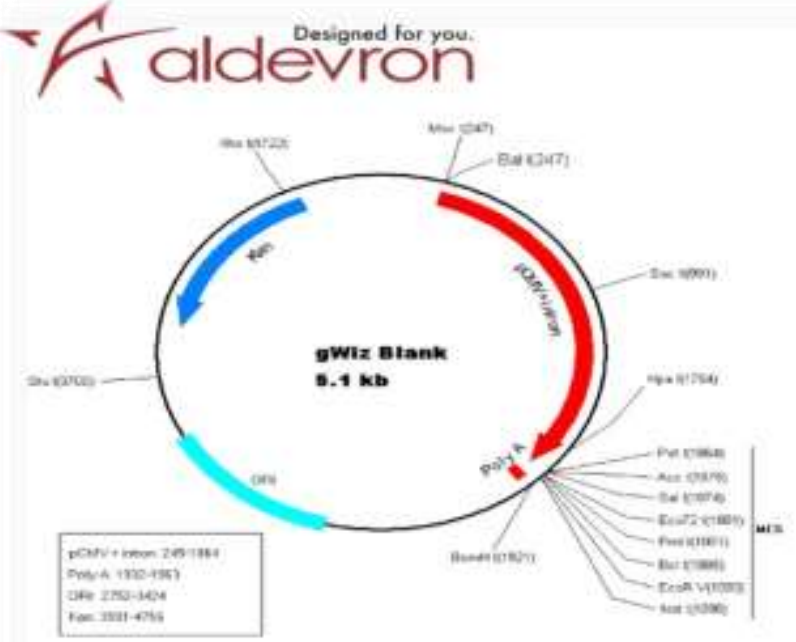

تصوير ا - نقشه زنتيكى يلاسميد gwiz حاوى زن NS3

يلاسميد HBx

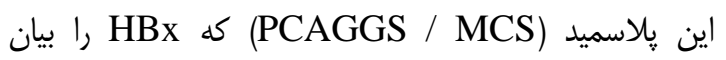

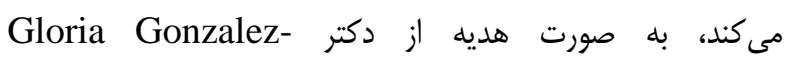
Aseguinolaza

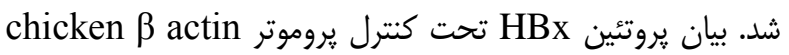

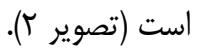

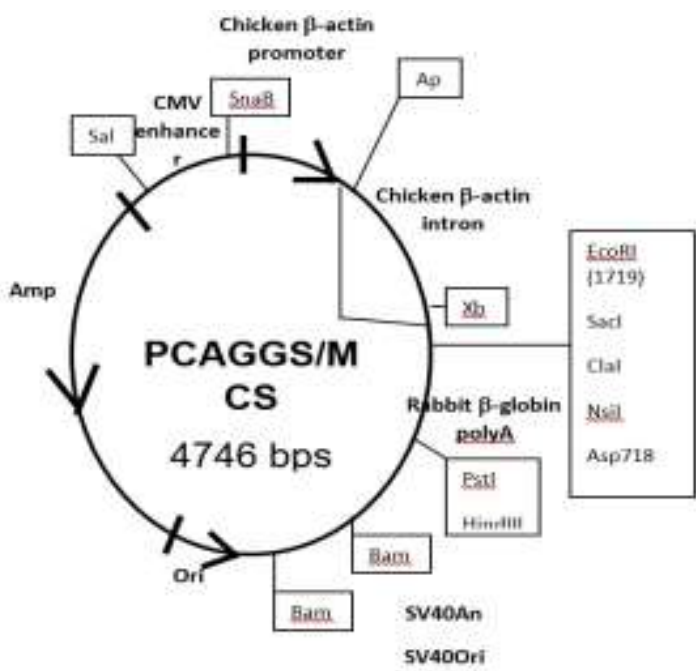

Polylinker

تصوير r- نقشه زنتيكى پالاسميد PCAGGS / MCS حاوى )ن HBx 
درجه سانتى

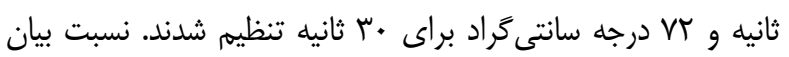

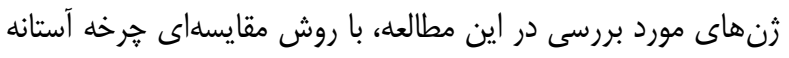

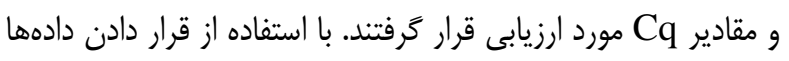

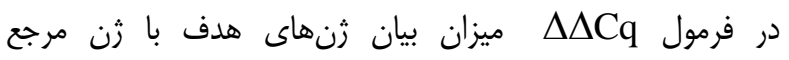
نرمال سازى شد. اطلاعات مربوط به يرايمرهاى استفاده

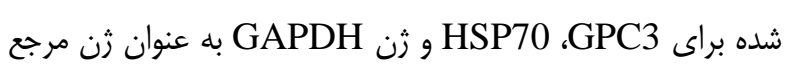

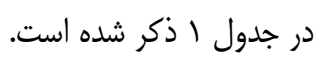

ميكروليتر)، cDNA به ميزان ( ميكروليتر و DEPC Water به من من مان ميزان 1 ميكروليتر مى باشند.

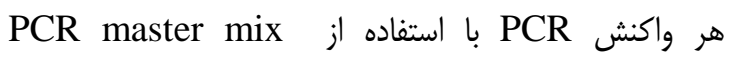
SYBER Green ور دستخاه (Applied Biosystems) ABI Step One (Applied Biosystems, Sequences Detection Systems. Focter City, CA) شركت سازنده انجام كرفت. • Real- شيكل براى هر خקخه

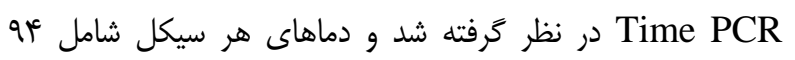

جدول ا - ويزَى هاى يرايمرهاى استفاده شده

\begin{tabular}{|c|c|c|c|c|}
\hline نام زن & توالى يرايمرها & محصول & كد زن در NCBI & 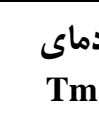 \\
\hline GPC3 & $\begin{array}{l}\text { FOR:5'-GGAGAGATACAGCCAGAAGGC-3' } \\
\text { REV:5'-AGGTGGTGATCTCGTTGTCC-3' }\end{array}$ & ה & NM_016697 & q. \\
\hline HSP & $\begin{array}{l}\text { FOR:5'-CGAGAGCCGGTCGTTCTTC-3' } \\
\text { REV:5'-CAGGTACGCCTCAGCGATCT-3' }\end{array}$ & va & NM_010479 & 9. \\
\hline GAPDH & $\begin{array}{l}\text { FOR:5'-TGGCCTTCCGTGTTCCTAC -3' } \\
\text { REV:5'-GAGTTGCTGTTGAAGTCGCA-3' }\end{array}$ & IVA & NM_001289726 & 9. \\
\hline
\end{tabular}

گروه تيمار نشده در نظر گرفته شدهاند و بر اين اساس با استفاده از

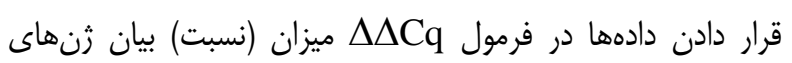
هدف نسبت به كَروه كنترل منفى محاسبه شد.

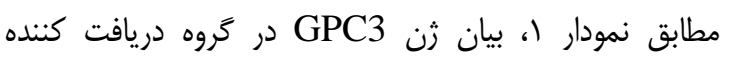

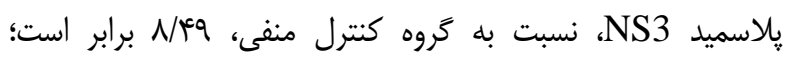

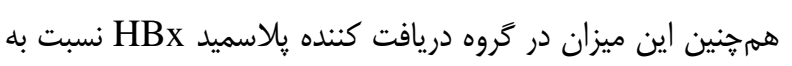
كروه كنترل منفى نيز افزايش دارد (V/VV برابر).

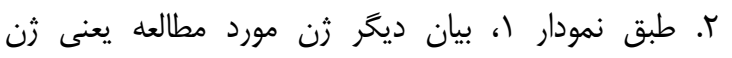

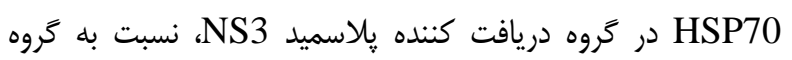

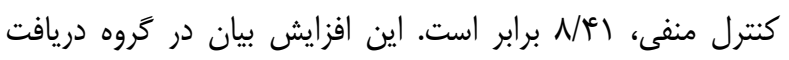

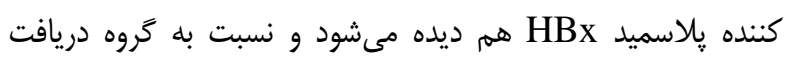

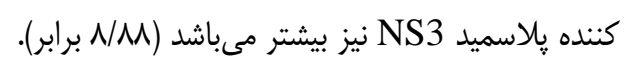

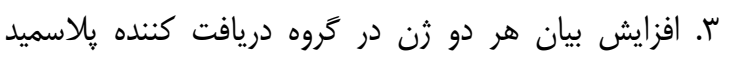

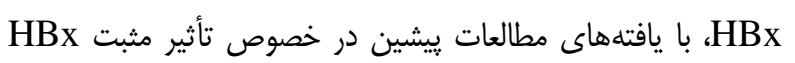
در افزايش بيان اين دو ثن مطابقت دارد.
تحليل آمارى همان گَونه كه قبلاً بيان شد، هر تروه شامل 1 نمونه بود و

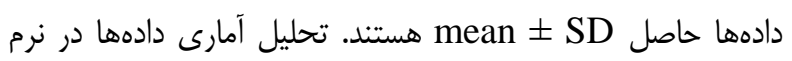
افزار 9.0.0 و و و با آزمون with Welch's correction معنى دارى، مقدار P value درسطح P> 0.05 در نظر كرفته شد.

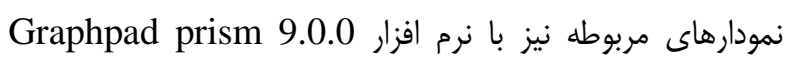
رسم شدند.

\section{يافتهها}

نتايج بهدست آمده از مقايسه بيان ثنها در كروههاى مختلف:

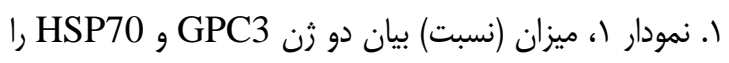

نشان مىدهد؛ همان طور كه ييش از اين كَته شد، بيان اين ثنها

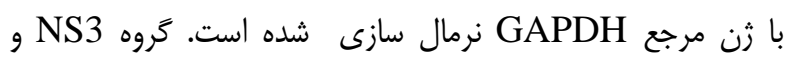

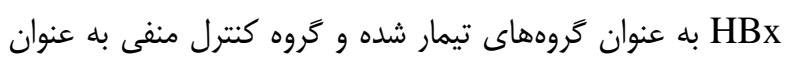


كروه دريافت كننده NS3 و HBx نيز با هم مقايسه شده است.

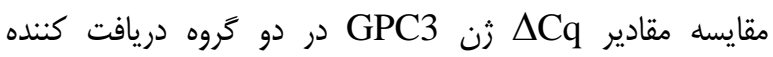
يلاسميد NS3 و HBx تفاوت معنى دارى را نشان نمى دهد. همين نتيجه در گروههاى مختلف آمده است.

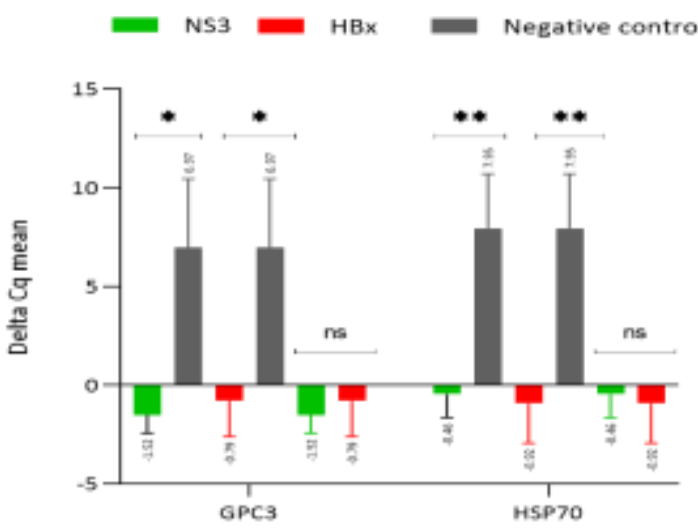

نمودار r - مقايسه مقادير SCq در هر تروه NS3 و HBx نسبت به تروه كنترل منفى. P>0.05: ns P<0.05: * P<0.01: **

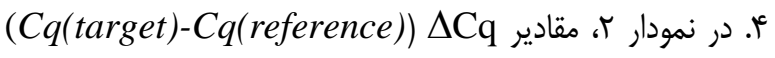
دو ثن GPC3 و HSP70 در گروه NS3 در مقايسه با كنترل منفى و HBx در مقايسه با كنترل منفى آورده شده است. همان

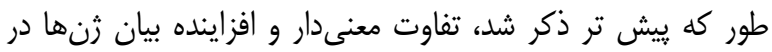
دو گروه NS3 و HBx در اينجا نيز مشهود است.

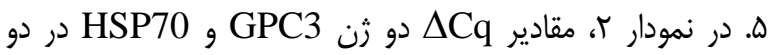

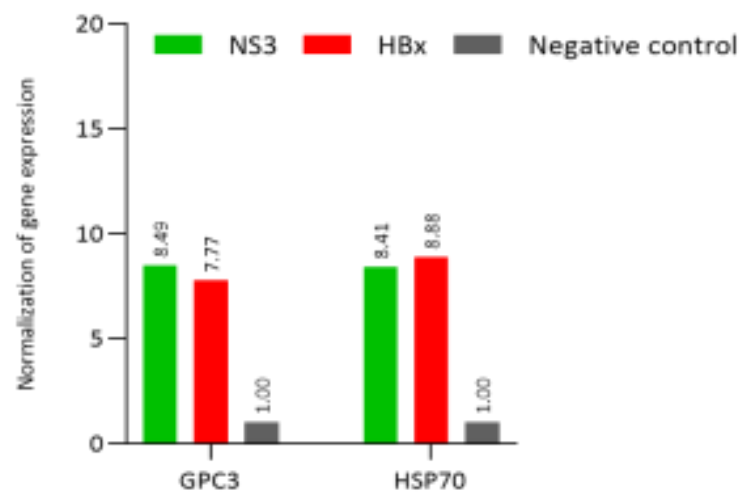

نمودار - نسبت بيان زنها در دو تروه NS3 و HBx.

جدول r- نسبت بيان زن هادر تروه هاى مختلف

\begin{tabular}{|c|c|c|c|}
\hline \multicolumn{3}{|c|}{ Pقادير P P P } & \multirow[b]{2}{*}{ 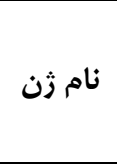 } \\
\hline تروه NS3 در مقايسه با تروه HBx & تروه HBx در مقايسه با تروه كنترل & تروه NS3 در مقايسه با تروه كنترل & \\
\hline$. / F \Delta \mid q$ &.$/ \cdot 148$ &.$/ . r \mathrm{q}$ & GPC3 \\
\hline.$/ 9 \mathrm{VF}$. & $.1 . . r T$ &.$/ . r^{\prime}$ & HSP70 \\
\hline
\end{tabular}

(19). در يك مطالعه نشان داده شد كه ويروس قادر به القاى سلولهاى بنيادى سرطانى در كشت سلول و تومورهاى زنوگرافت

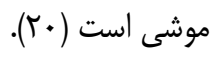

در مطالعات مختلف، يروتئين NS3 ويروس به عنوان يك

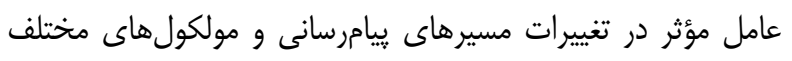

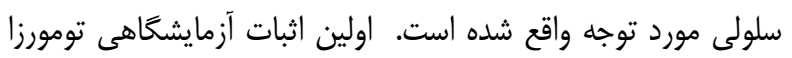
بودن Sakamuro توس Sak3 ومهكاران در رده سلولى غير تومورى فيبروبلاست موشى (NIH 3T3) انجام شد (أ). دو ثن ردان
عفونت مزمن با ويروس هياتيت C يك مشكل بهداشت جهانى

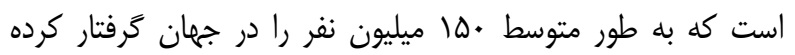
است.HCV خطر ابتلا به سرطان كبد را با تحريك التهاب و فيبروز

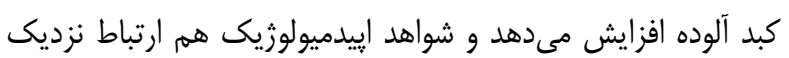
و واضحى را بين عفونت HCV و سرطان كبد نشان مىدهند.

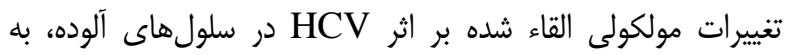
شكل معنادارى در گسترش و ييشرفت سرطان كبد، دخالت دارند 
انتخاب شده را در سطح mRNA بررسى كرديم و تحقيقات

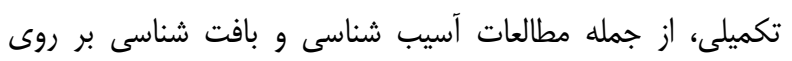
بافت كبد (مانند مطالعات ايمونوهيستوشيمى) و مطالعه در سطح بيان

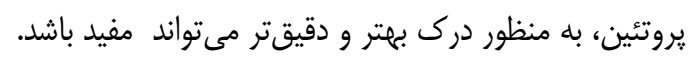

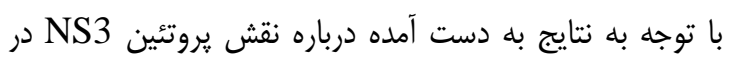

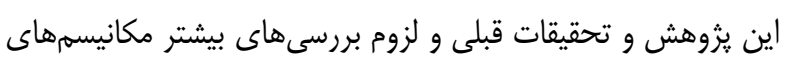

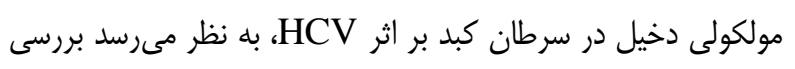

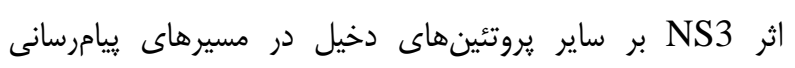

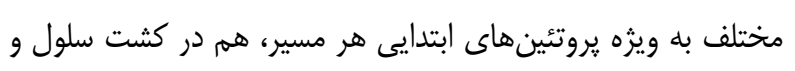
هم در مدلهاى حيوانى، مىتواند به درى مكانيسمهاى ايجاد سرطان كبد و درمان آن كمى كند.

به منظور دستيابى به نتايج دقيقتر و بررسى بهتر دمان صند نتايج اين تحقيق، تغيير در زمان خارج كردن كبد، تعداد دفعات

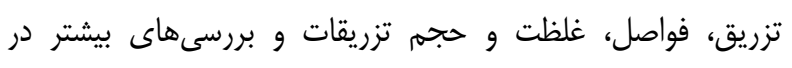

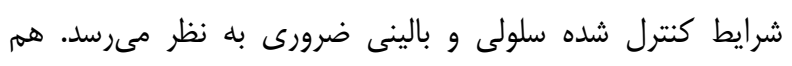

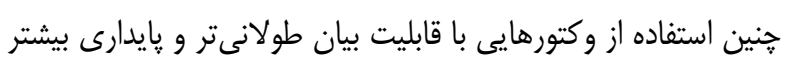

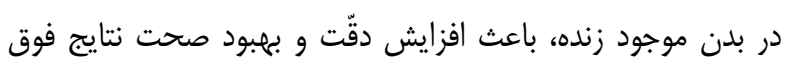

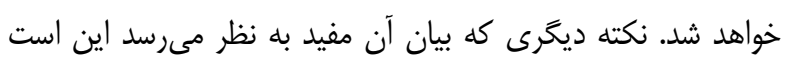

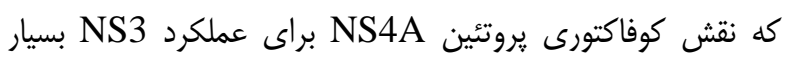

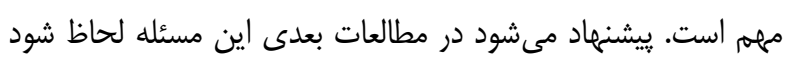
و از وكتورى كه هر دو يروتئين رادر بر دارد، استفاده شود.

\section{تقدير و تشكّر}

اين مقاله حاصل پايانامه كارشناسى ارشد با كد ايران داك

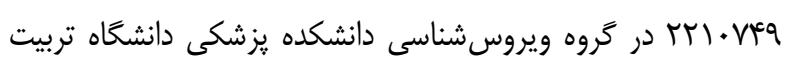
مدرس مىباشد.

\section{تضاد منافع}

نويسندكان مقاله اعلام مى دارند كه هيج گَونه تضاد منافعى در

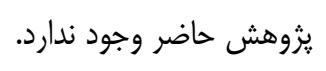

انتخاب شده در اين تحقيق، از نشانگرهاى هياتوسلولاركارسينوما

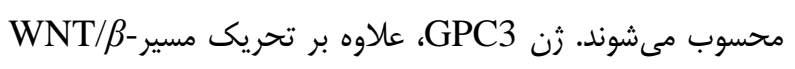
فادر است مسير ييامرسانى IGF Catenin فعال كند. اين يروتئين مىتواند سرطانزايى را از طريق واكنش بين IGF-II GPC3

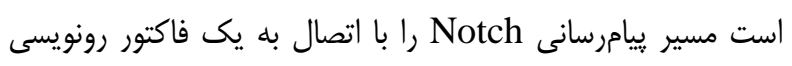

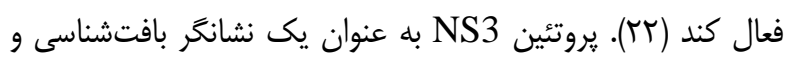
سرولوزى كشف شد كه بيان آن براى هياتوسلولاركارسينوما

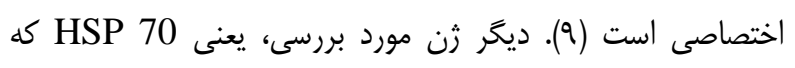

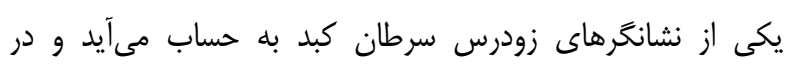

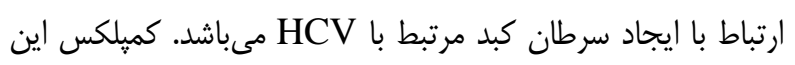

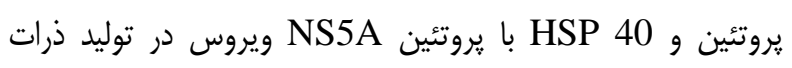
ويروسى جديد نقش دارد (بr). نويسندكان هدف از مطالعه حاضر را ارزيابى اثر يروتئين

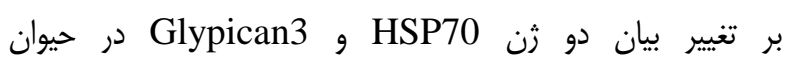
آزمايشَاهى عنوان كردهاند. از نظر داور محترم لازم بود نويسندًان

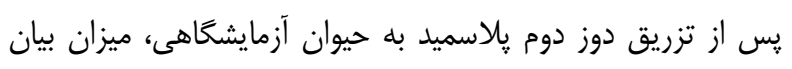

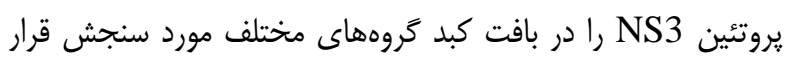

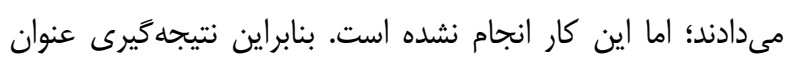

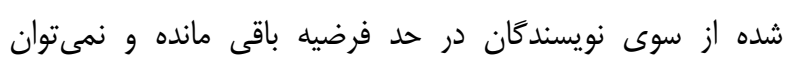

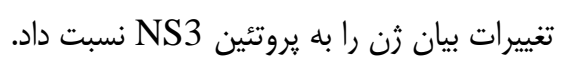

\section{نتيجه كيرى}

در اين تحقيق، در گروه دريافت كننده يلاسميد NS3 ميزان

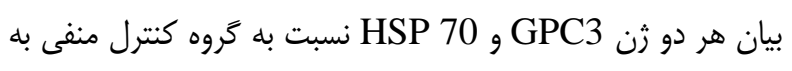

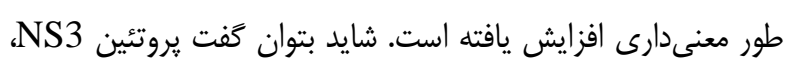

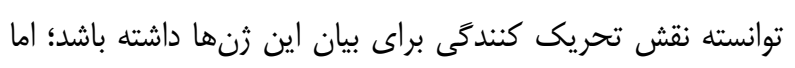

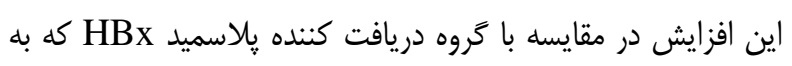
نحوى گروه كنترل مثبت به شمار مى آيند، تفاوت معنىدارى ندارد.

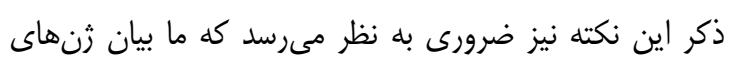


1- Heim MH. Innate immunity and HCV. J Hepatol. 2013; 58(3): 564-74 DOI: 10.1016/j.jhep.2012.10.005

2- Hiscott J, Lacoste J, Lin R. Recruitment of an interferon molecular signaling complex to the mitochondrial membrane: disruption by hepatitis C virus NS3-4A protease.Biochem Pharmacol. 2006; 72(11): 1477-84. DOI: $10.1016 /$ j.bcp.2006.06.030

3- He Q-Q, Cheng R-X, Sun Y, Feng D-Y, Chen Z-C, Zheng H. Hepatocyte transformation and tumor development induced by hepatitis C virus NS3 c-terminal deleted protein. World J Gastroenterol. 2003; 9(3): 474-8. DOI: $10.3748 /$ wjg.v9.i3.474

4- Kasprzak A, Adamek A. Role of hepatitis C virus proteins (C, NS3, NS5A) in hepatic oncogenesis. Hepatol Res. 2008; 38(1): 1-26. DOI: 10.1111/j.1872-034X.2007.00261.x

5- Jeong SW, Jang JY, Chung RT. Hepatitis C virus and hepatocarcinogenesis. Clin Mol Hepatol. 2012; 18(4): $347-56$. DOI: $10.3350 / \mathrm{cmh} .2012 .18 .4 .347$

6- Mikhail S, He AR. Liver Cancer Stem Cells. Int J Hepatol. 2011; 2011: 486954. DOI: 10.4061/2011/486954

7- Wang B, Jacob ST. Role of cancer stem cells in hepatocarcinogenesis.Genome Med. 2011; 3(2): 1-6. DOI: $10.1186 / g m 225$

8- Singhal A, Jayaraman M, Dhanasekaran DN, Kohli V. Molecular and serum markers in hepatocellular carcinoma: Predictive tools for prognosis and recurrence. Crit Rev Oncol Hematol. 2012; 82(2): 116-40. DOI: 10.1016/j.critrevonc.2011.05.005

9- Shirakawa H, Kuronuma T, Nishimura Y, Hasebe T, Nakano M, Gotohda N, et al. Glypican-3 is a useful diagnostic marker for a component of hepatocellular carcinoma in human liver cancer. Int J Oncol. 2009; 34(3): 649-56. DOI: 10.3892/ijo_00000190

10- Filmus J, Capurro M. Glypican-3: a marker and a therapeutic target in hepatocellular carcinoma. FEBS J. 2013; 280(10): 2471-6. DOI: 10.1111/febs.12126

11- Takashima M, Kuramitsu Y, Yokoyama Y, Iizuka N, Toda T, Sakaida I, et al. Proteomic profiling of heat shock protein 70 family members as biomarkers for hepatitis $\mathrm{C}$ virus-related hepatocellular carcinoma. Proteomics. 2003; 3(12): 2487-93. DOI: 10.1002/pmic.200300621

12- Lagana SM, Salomao M, Bao F, Moreira RK, Lefkowitch JH, Remotti HE. Utility of an Immunohistochemical Panel Consisting of Glypican-3, Heat-shock Protein-70, and Glutamine Synthetase in the Distinction of Low-grade Hepatocellular Carcinoma From Hepatocellular Adenoma. Appl Immunohistochem Mol Morphol. 2013; 21(2): 170-6 10.1097/PAI.0b013e31825d527f. DOI: 10.1097/PAI.0b013e31825d527f

13- Azam F, Koulaouzidis A. Hepatitis B virus and hepatocarcinogenesis. Ann Hepatol. 2008; 7(2): 125-9. DOI: 10.1016/S1665-2681(19)31867-8

14- Ng S-A, Lee C. Hepatitis B virus X gene and hepatocarcinogenesis. J Gastroenterol. 2011; 46(8): 974-90. DOI: $10.1007 / \mathrm{s} 00535-011-0415-9$

15- Sun Q, Wang Y, Zhang Y, Liu F, Cheng X, Hou N, et al. Expression profiling reveals dysregulation of cellular cytoskeletal genes in $\mathrm{HBx}$-induced hepatocarcinogenesis. Cancer Biol Ther. 2007; 6(5): 668-74. DOI: $10.4161 /$ cbt.6.5.3955

16- Gouas DA, Shi H, Hautefeuille AH, Ortiz-Cuaran SL, Legros PC, Szymanska KJ, et al. Effects of the TP53 p.R249S mutant on proliferation and clonogenic properties in human hepatocellular carcinoma cell lines: interaction with hepatitis B virus X protein. Carcinogenesis. 2010; 31(8): 1475-82. DOI: 10.1093/carcin/bgq118

17- Xie H-Y, Cheng J, Xing C-Y, Wang J-J, Su R, Wei X-Y, et al. Evaluation of hepatitis B viral replication and proteomic analysis of HepG2. 2.15 cell line after knockdown of HBx. Hepatobiliary Pancreat Dis Int. 2011; 10(3): 295-302. DOI: 10.1016/s1499-3872(11)60049-0

18- Khanlari Z, Sabahi F, Hosseini SY, Ghaderi M. HCV NS3 Blocking Effect on IFN Induced ISGs Like Viperin and IL28 With and Without NS4A. Hepat Mon. 2014; 14(6): e17822. DOI: 10.5812/hepatmon.17822 
19- Vermehren J, Aghemo A, Falconer K, Susser S, Lunghi G, Zeuzem S, Colombo M, Weiland O, Sarrazin C. Clinical significance of residual viremia detected by two realtime PCR assays for response-guided therapy of HCV genotype 1 infection.J Hepatol. 2014; 60(5): 913-9. DOI: 10.1016/j.jhep.2014.01.002

20- Ali N, Allam H, May R, Sureban SM, Bronze MS, Bader T, et al. Hepatitis C virus-induced cancer stem cell-like signatures in cell culture and murine tumor xenografts. J Virol. 2011; 85(23): 12292-303. DOI: 10.1128/JVI.0592011

21- Cheng W, Tseng C-J, Lin TTC, Cheng I, Pan H-W, Hsu H-C, Lee Y. Glypican-3- mediated oncogenesis involves the Insulin-like growth factor-signaling pathway. Carcinogenesis. 2008; 29(7): 1319-26. DOI: $10.1093 /$ carcin/bgn091

22- Iwai A, Takegami T, Shiozaki T, Miyazaki T. Hepatitis C virus NS3 protein can activate the Notch-signaling pathway through binding to a transcription factor, SRCAP. PloS one. 2011; 6(6): e20718. DOI: 10.1371/journal.pone.0020718

23- Gonzalez O, Fontanes V, Raychaudhuri S, Loo R, Loo J, Arumugaswami V, Sun R, Dasgupta A, French S. The heat shock protein inhibitor Quercetin attenuates hepatitis C virus production. Hepatology. 2009; 50(6): $1756-64$. DOI: $10.1002 /$ hep. 23232 